\section{Valsa brasileira: uma análise dos governos Lula e Dilma}

\section{Brazilian waltz: an analisys of the Lula and Dilma governments}

CARVALHO, Laura. Valsa brasileira: do boom ao caos econômico. São Paulo, Todavia, 2018. 192 páginas.

Márcio Kleber Morais Pessoa $(1)$

(i) https://orcid.org/0000-0002-1371-5481

André Haguette (2)

https://orcid.org/0000-0002-2962-6440

DOI: $10.1590 / 3410105 / 2019$

(1) Universidade Estadual do Ceará (UECE), Fortaleza - CE, Brasil.E-mail: mkpceara@hotmail.com

(2) Universidade Federal do Ceará (UFC), Fortaleza - CE, Brasil. E-mail: haguetteandre@gmail.com

O excelente livro de Laura Carvalho se impóe como leitura obrigatória para quem quer entender o percurso da economia brasileira de 2003 a 2016, ou, dito de outra forma, para compreender a valsa da economia brasileira a partir do governo Lula (2003-2010), passando pelo governo Dilma (20112016) até chegar ao governo Temer (2016-2018).

Para a autora e a totalidade dos estudiosos do assunto, esse período apresenta uma característica peculiar: a economia brasileira foi "do boom ao caos", como o subtítulo do livro deixa claro. Seu objetivo é, portanto, explicar esse fenômeno, como ela mesma esclarece logo no primeiro parágrafo da introdução:

Como a economia de um país continental evoluiu, em apenas sete anos, da euforia de um cenário de crescimento bem acima da média das últimas décadas, com vigorosa geração de empregos formais e alguma redução das desigualdades, para uma das maiores crises de sua história (p. 9).

Crise que continua severa até os dias de hoje, início de 2019. Para um fenômeno tão inesperado e marcante, não faltam explicaçóes. A autora levanta três hipóteses, analisadas à luz dos contextos "um pouco de sorte e alguns acertos" - para decifrar o crescimento - e "um pouco de azar e erros significativos" - para explicar a desaceleração econômica e a crise que se segue.

A primeira hipótese - explicação muito comum - é de que a economia brasileira cresceu de forma acelerada, entre 2003 e 2011, favorecida pela alta nos preços das commodities que exportamos: petróleo, minério de ferro e soja. O Brasil deu sorte por quatro ou cinco anos, mas o azar voltou a prevalecer e arrastou o PIB para baixo. A segunda hipótese recorre a uma sucessão de erros que minaram as condições macroeconômicas virtuosas, implantadas no fim da década de 1990: estabilização dos preços e o famoso tripé macroeconômico composto por metas de inflação, superávit primário e câmbio flutuante. E a terceira hipótese: a crise seria essencialmente política, causada pela propaganda negativa da imprensa, a má-fé do Congresso ou até mesmo por um boicote do empresariado. Seriam, então, os acertos, dos governos Lula e Dilma os responsáveis pela crise ao provocar incômodo às elites econômicas e financeiras do país.

Laura Carvalho náo se alonga em discutir essas hipóteses nem cita seus autores, embora volte a referir-se a elas e a rejeitá-las na página $41 . \mathrm{Na}$ realidade, o livro não é estritamente acadêmico, uma vez que se originou de artigos da autora publicados no jornal Folha de S.Paulo, entre julho de 2015 e dezembro de 2017. O resultado é um texto de invejável leveza sem diminuir a pertinência da análise a que a autora se propóe. E, assim, as três hipóteses sucintamente explicadas são as que apareceram no quotidiano das discussóes nos jornais e nos debates acadêmicos, nas comparaçóes entre os governos de FHC e Lula e nas discussóes sobre os governos Dilma, sendo formuladas ora para valorizar a continuidade com a política de FHC que Palocci vai imprimir na economia no início do governo Lula, ora para justificar o acúmulo de obstáculos à política de Lula no final de seu segundo mandato. A esse efeito, a autora cita Henrique Meireles nas páginas 14 e 15. Por sua vez, o argumento da alta dos preços das commodities - que de fato ocorreu - foi, muitas vezes, utilizado para pôr panos quentes no sucesso da política econômica de Lula. Carvalho, de maneira assertiva, separa os prós e os contras 
desses dois argumentos na elaboraçáo de seu próprio pensamento.

A terceira hipótese rejeitada diz respeito a "uma das maiores crises" do país no governo Dilma. Aqui a autora dialoga abertamente com as ideias de André Singer (2015), defendidas no ensaio "Cutucando onças com varas curtas". Se Singer argumenta que a burguesia industrial se afastou da linha desenvolvimentista de Dilma por uma "greve de investimento", Laura Carvalho vê que "havia razôes econômicas suficientes para que os empresários não realizassem maiores investimentos" (pp. 76-77).

Essas três hipóteses postas e rejeitadas, o livro torna-se original, competente, arguto e cativante em, recusando basear-se em uma única causa, construir uma explicação própria, com dados empíricos e análises rigorosas.

O Estado havia sido decisivo na expansão do mercado interno brasileiro entre 2006 e 2010, através de políticas de transferências de renda e aumento do salário mínimo, junto com a ampliação dos investimentos em infraestrutura física e social. No entanto, no final do segundo mandato do presidente Lula, crescia a visão de que tal estratégia de crescimento, erroneamente interpretada como "liderada pelo consumo", era insustentável. Empresários do setor industrial e boa parte dos economistas defendiam medidas que reduzissem os custos das empresas nacionais e elevassem sua competitividade diante da concorrência estrangeira.

A presidente Dilma atende a tais demandas: reduz a taxa de juros, desvaloriza o real, subsidia a lucratividade dos empresários por meio de desoneraçóes tributárias, controle de tarifas energéticas e crédito a juros mais baixos. Essas medidas, de alto custo e pouco eficazes no estímulo ao crescimento, têm impacto negativo sobre as receitas do governo e dificultam a estabilizaçâo da dívida pública (p. 11).

A esse conjunto de medidas, a autora denomina "Agenda Fiesp". Sua tese posta, Laura Carvalho vai dividir em cinco capítulos seu esforço para analisar os pilares do que qualifica metaforicamente de "valsa brasileira". (1) "O Milagrinho brasileiro: um passo à frente", (2) "A Agenda Fiesp: um passo ao lado" e (3) "A panaceia fiscal: um passo atrás". O quarto capítulo, "Acertando os passos", traz propostas de atuação econômica governamental para tirar o país da crise, atendendo às demandas da maioria dos brasileiros. No quinto e último capítulo, "Dançando com o diabo", a autora defende que o crescimento econômico "não é um facilitador apenas de melhorias materiais, mas também da liberdade, da tolerância, da justiça e da democracia”" (p. 181), e convida à instauraçáo de uma política institucional aberta à participação mais efetiva da sociedade.

No primeiro capítulo, a autora reconhece que as altas taxas de crescimento da economia chinesa e sua demanda crescente pelas chamadas commodities tiveram impacto positivo e beneficiaram o conjunto das economias latino-americanas no alvorecer do século XXI. A nossa economia salta de uma taxa anual de crescimento médio de $2,1 \%$ nos anos de 1980 e 1990 para 3,7\% na década de 2000, o que Edmar Bacha chamou de "Milagrinho brasileiro". Mas, argumenta a economista, o aumento da demanda mundial por nossos produtos perde influência após 2005 e o mercado interno começa a crescer mais rapidamente, graças à expansão do consumo das famílias, isso sustentado em três pilares das políticas adotadas pelo governo Lula: (1) o pilar da distribuição de renda, via Bolsa Família e elevação do salário mínimo; (2) o do acesso ao crédito; e (3) o dos investimentos públicos. Mas a crise de 2008 (tsunami ou marolinha?) provoca contração do crédito, queda no preço das commodities e forte saída de capitais estrangeiros, o que resulta em uma contração substancial da demanda doméstica e dois semestres consecutivos de queda do PIB. O processo de crescimento mostra seus limites via desequilíbrio externo e estrutura produtiva, uma inflação de serviços e concentração de renda no topo. "A superaçâo desses limites exigia encarar de frente os conflitos mais acirrados, de modo a conferir maior solidez aos pilares do modelo" (p. 53), o que, com toda evidência, não foi feito.

O segundo capítulo, dedicado aos governos da presidente Dilma Rousseff, explica que, diante da falta de competitividade da indústria nacional e dos desequilíbrios externos, a presidente tentou encarar 
os conflitos, mas o fez com políticas referendadas e exigidas por associaçóes patronais, como a Fiesp (a Agenda Fiesp a que a autora se refere).

Esse receituário buscava estimular a competitividade da indústria nacional, a fim de sanar uma das deficiências do período anterior, por meio da redução dos juros (que estimulariam os investimentos privados) e a desvalorização do real (que tornariam os produtos nacionais mais atraentes para o exterior). Todavia, isso geraria aumento da inflação, logo, deveria haver uma medida para controlar os gastos, o que viria com um ajuste fiscal, que impactou os investimentos públicos. Outras medidas beneficiaram diretamente os industriais: desoneraçóes tributárias (que foram centrais na política econômica do primeiro governo Dilma) e expansão de crédito do BNDES. Com o objetivo de controlar a inflação, fez-se represamento das tarifas de energia, bancado com dinheiro público. ${ }^{1}$ Resumindo: uma tentativa de aumento da produtividade voltada para o exterior, enquanto o mercado interno se retrairia. "Pode-se dizer com segurança que os resultados [da adoção da Agenda Fiesp] foram desastrosos" (p. 59).

Desastrosos pelas seguintes razóes: as exportações tiveram queda de crescimento, entre 2010 e 2012. A inflação começou a fugir de controle. Esse resultado fez o Banco Central voltar a elevar os juros, a partir de abril de 2013, na tentativa de controlar os preços. Ademais, o almejado investimento privado não ocorreu, segundo a autora, por três motivos: (1) o nível de consumo estava em queda; (2) os industriais estavam afundados em dívidas do período anterior; e (3) crescimento da financeirização da economia, em detrimento do setor produtivo. Assim, não havia motivo para se investir, servindo então as desoneraçóes tributárias para recomposiçấo da margem de lucros dos empresários. Tudo isso acabou sendo dissecado durante os debates referentes às eleições de 2014.

O terceiro capítulo já conta uma história bem mais comentada e conhecida, a começar pela nomeação inesperada do economista ortodoxo Joaquim Levy, vista como estelionato eleitoral. As novas políticas fiscal e monetária juntamente com a crise política, os efeitos da Lava Jato sobre os setores da construção civil e do petróleo, escreve Laura Carvalho, com a forte desvalorização do real e a queda dos preços dos produtos exportados contribuíram "para transformar a desaceleração econômica dos anos 2011-14 em uma das maiores crises de nossa história” (p. 98) e a uma reversão das conquistas sociais dos anos 2000, com quedas acentuadas do PIB e do consumo das famílias, além de inflação chegando a dois dígitos.

No capítulo, a autora analisa também a "panaceia do impeachment" e os equívocos da política econômica da administração Temer, embora "ainda que tenha contado com a ajuda de fatores temporários, como a supersafra de soja e a liberação para o saque de contas inativas do FGTS, os números do PIB dos primeiros trimestres de 2017 mostraram que "a economia do país parou de piorar. $\mathrm{O}$ fundo do poço chegou cerca de um ano depois do previsto, mas chegou" (p. 143). Como vimos anteriormente, os dois últimos capítulos, o quarto e o quinto, expóem a contribuição da autora para a recuperação da economia, deixando a "década perdida” para trás; essa contribuição, vale dizer, vai na direção oposta ao modelo adotado pelo governo Temer. A seguinte citação do Banco Mundial feita pela autora na página 141 bem exemplifica seu posicionamento teórico:

A princípio, a redução dos gastos não é a única estratégia para restaurar o equilíbrio fiscal, mas é uma condição necessária... Certamente, há escopo para aumentar a tributação dos grupos de alta renda, por exemplo, por meio de impostos sobre a renda, patrimônio ou ganhos de capital e reduzir a dependência dos tributos indiretos, que sobrecarregam os mais pobres.

Vê-se, portanto, que o livro Valsa brasileira conta uma história, faz uma narrativa das causas que, em sete anos, levaram a nossa economia do "boom ao caos" e, nos anos que se seguiram, a uma das maiores crises de nossa história, de difícil e longa recuperação. A solidez da argumentação fundamentada em dados empíricos confere credibilidade às teses desenvolvidas, em uma escrita despretensiosa, sem academicismo e arrogância, que torna a leitura extremamente prazerosa, além de apresentar uma perspectiva teórica de análise diferente das análises ortodoxas tanto da direita como da esquerda. 
Laura Carvalho não se esquiva do debate e da polêmica (em duas ocasióes, por exemplo, ela se opóe a argumentos de André Singer); lembramos que o livro recorreu a artigos da autora antes publicados na Folha de S.Paulo, o que certamente ajuda a compreender a razão da leveza da redação. Mas, acima de tudo, causa alívio e admiração ver uma acadêmica executar análises sem parti pris, sem ódio, mas também sem condescendência com o rigor dos dados, discordando com argumentos, com liberdade e integridade, das posiçóes estabelecidas, coisa rara nos dias sectários de hoje. Por isso, Laura Carvalho representa o novo nas discussóes em curso e isso em um livro apaixonante, que recomendamos sem hesitação a qualquer pessoa que, de mente aberta, queira entender a trajetória econômica do país nos últimos dezesseis anos.

\section{Notas}

1 Apesar disso, as tarifas foram bruscamente reajustas em 2015, gerando bastante insatisfação.

\section{BIBLIOGRAFIA}

SINGER, André. (2015), "Cutucando onças com varas curtas. O ensaio desenvolvimentista no primeiro mandato de Dilma Rousseff (20112014)". Novos Estudos Cebrap, 102: 39-67. 
Revista Brasileira de Ciências Sociais (2019) 34(101): e3410105

DOI: $10.1590 / 3410105 / 2019 \mathrm{ER}$

E-location: e3410105ER

\section{ERRATA}

Na resenha Valsa brasileira: uma análise dos governos Lula e Dilma, DOI: 10.1590/3410105/2019, publicada na Revista Brasileira de Ciências Sociais, 34(101):e3410105, página 1, na filiação institucional do primeiro autor, Márcio Kleber Morais Pessoa:

Onde se lia:

Universidade Estadual do Ceará (UESC), Fortaleza - CE, Brasil.

Leia-se:

Universidade Estadual do Ceará (UECE), Fortaleza - CE, Brasil. 